\title{
Heart transplantation at the Peruvian National Heart Institute: One-decade single-center experience
}

\author{
Miguel Pinto-Salinas ${ }^{1}$, Julio Morón-Castro ${ }^{1}$, Fernando Chavarri-Velarde ${ }^{1}$, Franz \\ Soplopuco-Palacios ${ }^{2}$, Luis Palma-Ortecho ${ }^{3}$, and Miguel Lescano-Alva ${ }^{4}$ \\ ${ }^{1}$ Universidad Nacional Mayor de San Marcos \\ ${ }^{2}$ Department of Cardiovascular Surgery Instituto Nacional Cardiovascular "Carlos Alberto \\ Peschiera Carrillo" Lima Peru \\ ${ }^{3}$ Department of Cardiopediatrics Instituto Nacional Cardiovascular "Carlos Alberto \\ Peschiera Carrillo" Lima Peru \\ ${ }^{4}$ Department of Clinical Cardiology Instituto Nacional Cardiovascular "Carlos Alberto \\ Peschiera Carrillo" Lima Peru
}

October 26, 2021

\begin{abstract}
Background: Heart transplantations are ideal for most patients with end-stage heart failure refractory to medical treatment. The transplantation program at the Peruvian National Heart Institute started with a 10-year-continuity in 2010. Objective: To report the results of a 10-year heart transplantation experience at the Peruvian National Heart Institute. Methods: We studied 83 patients who underwent orthotopic heart transplantation at a single center between January 2010 and December 2019. The recipients' profiles and survival were analyzed according to sex and age group, ensuring the information's confidentiality. Results: The recipients' mean age was $41.2 \pm 17$ years, $88 \%$ were adult, and $68.7 \%$ were male. The main indications for transplantation were idiopathic dilated cardiomyopathy. $85.5 \%$ of recipients were clinically categorized as INTERMACS Profile 1 to 3 before transplantation. There was a significant difference between sexes regarding the preoperative left ventricular ejection fraction and between age groups regarding the waiting time. The average ischemia time was 3.1 hours, operating time was 6.1 hours, cardiopulmonary bypass time was 3 hours, and aortic cross-clamp time was 1.7 hours. The principal early postoperative complications were hematological disorders and acute kidney failure. The principal late ones were kidney failure and severe anemia. The postoperative mortality was $15.9 \%$, and the principal causes were infection and then acute rejection. The survival at one, five, and ten years was $87.5 \%, 79.8 \%$, and $79.8 \%$, respectively. The survival results were not influenced by sex or age group. Conclusion: Our patients' postoperative complications, mortality, and survival rates coincided with those reported by the ISHLT registry.
\end{abstract}

\section{Heart transplantation at the Peruvian National Heart Institute: One-decade single-center ex- perience}

\section{Authors:}

Pinto-Salinas $\mathrm{M}^{1}$, Morón-Castro $\mathrm{J}^{1,2}$, Chavarri-Velarde $\mathrm{F}^{1,3}$, Soplopuco-Palacios $\mathrm{F}^{2}$, Palma-Ortecho $\mathrm{L}^{3}$, Lescano-Alva $\mathrm{M}^{4}$

\section{Affiliation:}

1. Medical School, Universidad Nacional Mayor de San Marcos, Lima, Peru.

2. Department of Cardiovascular Surgery, Instituto Nacional Cardiovascular "Carlos Alberto Peschiera Carrillo," Lima, Peru. 
3. Department of Cardiopediatrics, Instituto Nacional Cardiovascular "Carlos Alberto Peschiera Carrillo," Lima, Peru.

4. Department of Clinical Cardiology, Instituto Nacional Cardiovascular "Carlos Alberto Peschiera Carrillo," Lima, Peru.

\section{Running title:}

Heart transplantation at Peru

\section{Correspondent author}

Miguel Pinto-Salinas MD

Universidad Nacional Mayor de San Marcos

755 Miguel Grau Avenue, Cercado de Lima, 15001 Lima, Peru

e-mail: miguel.pintosal@gmail.com

Funding: None

\section{Meeting presentation}

This manuscript was presented as part of Miguel Pinto-Salinas's undergraduate thesis's support performed at the Universidad Nacional Mayor de San Marcos Medical School on March 2, 2020 (1)(1).

\section{ABSTRACT}

Background: Heart transplantations are ideal for most patients with end-stage heart failure refractory to medical treatment. The transplantation program at the Peruvian National Heart Institute started with a 10-year-continuity in 2010 .

Objective: To report the results of a 10-year heart transplantation experience at the Peruvian National Heart Institute.

Methods: We studied 83 patients who underwent orthotopic heart transplantation at a single center between January 2010 and December 2019. The recipients' profiles and survival were analyzed according to sex and age group, ensuring the information's confidentiality.

Results: The recipients' mean age was $41.2 \pm 17$ years, $88 \%$ were adult, and $68.7 \%$ were male. The main indications for transplantation were idiopathic dilated cardiomyopathy. $85.5 \%$ of recipients were clinically categorized as INTERMACS Profile 1 to 3 before transplantation. There was a significant difference between sexes regarding the preoperative left ventricular ejection fraction and between age groups regarding the waiting time. The average ischemia time was 3.1 hours, operating time was 6.1 hours, cardiopulmonary bypass time was 3 hours, and aortic cross-clamp time was 1.7 hours. The principal early postoperative complications were hematological disorders and acute kidney failure. The principal late ones were kidney failure and severe anemia. The postoperative mortality was $15.9 \%$, and the principal causes were infection and then acute rejection. The survival at one, five, and ten years was $87.5 \%, 79.8 \%$, and $79.8 \%$, respectively. The survival results were not influenced by sex or age group.

Conclusion: Our patients' postoperative complications, mortality, and survival rates coincided with those reported by the ISHLT registry.

Keywords: Heart transplantation, heart failure, transplant recipients, cardiac surgery, survival.

\section{Introduction}

According to the International Society of Heart and Lung Transplantation (ISHLT), heart transplantations (HTx) are the ideal treatment for patients with end-stage heart failure (EHF) refractory to medical treatment (2). Currently, worldwide survival is favorable, $80 \%$ at one year and $60 \%$ at five years, mainly due to the development and improvement of immunosuppressive treatment, the strict selection of receptors, and the 
early diagnosis of postoperative complications (3). Thus, approximately $124700 \mathrm{HTx}$ have been performed since Barnard's team performed the first successful HTx in 1967, with approximately 5000 transplants per year to date $(2,4)$.

These reports include mostly data from Europe and North America (5). However, the Latin American and Caribbean Transplantation Society reports a registry of 9000 patients with HTx by 2016 in Latin America. In its registry, Peru shows around 97 HTx since 1993, considered one of the lowest regional rates (6). It was not until 1972 that the first HTx was carried out in Peru by Molina's team at Hospital Nacional Edgardo Rebagliati Martins. However, it was an isolated case, and it was until 1993 when the first Peruvian HTx National Program was created with Pacheco's team with some continuity (7). For a while since the late 1990s, HTxs were not carried out. It is impressive due to changes in government policy and sociocultural factors, as in other developing countries of the time, until the program was restarted at the Peruvian National Heart Institute (INCOR) in $2010(2,8)$. Since then, it has been the only national reference center for HTx in Peru.

Given the lack of systematic reporting of experiences with regional programs, we sought to compare transplant recipients' profiles and survival from the Peruvian experience versus international benchmark results. Furthermore, contributing to the global understanding of these procedures' performance. Therefore, this study's objective was to report the results of a 10-year HTX experience at INCOR.

\section{Materials and methods}

IRB Approval: This manuscript had an ethics approval by the hospital Institutional Review Board.

Consent Statement: All research subjects signed and accepted the institutional informed consent to carry out research work.

\section{Clinical trial registration: N/A}

Population and Study Design

There were 86 records of patients who underwent human-to-human orthotopic HTx at INCOR's database from January 2010 to December 2019. We excluded three patients, two of whom were transplanted in other centers, and one medical record was unavailable at the study time. Therefore, we present 83 cases. There was no heart retransplantation, and none of the recipients had to undergo major cardiac surgery after the HTx. The profile of the recipients and their survival were analyzed according to sex and age group. The confidentiality of the data was ensured.

\section{Surgical Procedure}

The surgical technique currently performed at INCOR is the bicaval/unipulmonar described by Sarsam et al. (10).

\section{Antibiotic Prophylaxis Protocol}

Intravenous cefepime is included as antibiotic prophylaxis before transplantation. If cephalosporin allergy is present, vancomycin is chosen. It is prescribed at discharge oral trimethoprim/sulfamethoxazole once daily, oral nystatin three times daily, after meals, rinsing and swallowing, and topical clotrimazole twice daily. Oral valganciclovir is added on intermediate to high-risk patients once daily.

\section{Immunosuppression Protocol}

Our immunosuppressive protocol has been based on triple therapy: corticosteroids, a calcineurin inhibitor, and an antiproliferative agent. Induction therapy consisted of intravenous thymoglobulin $(1.5 \mathrm{mg} / \mathrm{kg} / \mathrm{day})$ during the first five postoperative days and was preceded by acetaminophen, methylprednisolone, and chlorphenamine. Thymoglobulin dose was decreased $(1 \mathrm{mg} / \mathrm{kg} /$ day $)$ if leukocytes $<3000$ cells $/ \mathrm{mm}^{3}$ or platelets $<75000$ cells $/ \mathrm{mm}^{3}$, and discontinued if leukocytes $<2000$ cells $/ \mathrm{mm}^{3}$ or platelets $<50000$ cells $/ \mathrm{mm}^{3}$. Basiliximab (20 mg) is also administrated, one drug regimen two hours preoperatively, and another on the fourth postoperative day. The corticosteroid regimen started with intravenous methylprednisolone $(500 \mathrm{mg})$ in the 
preoperative period and upon release of the aortic clamp, and $125 \mathrm{mg} 3$ times daily on the first postoperative day. Prednisone $(1 \mathrm{mg} / \mathrm{kg} /$ day $)$ was continued twice daily, with the dose being decreased $5 \mathrm{mg}$ every three days until reaching approximately $0.2 \mathrm{mg} / \mathrm{kg} /$ day by the sixth week. After six months of treatment, it was tapered at $5 \mathrm{mg}$ /day. Our institute currently employs oral tacrolimus $(0.05-0.1 \mathrm{mg} / \mathrm{kg} /$ day $)$ twice daily as a calcineurin inhibitor and adjusted according to renal function. It is titrated to achieve a serum level between $15 \mathrm{ng} / \mathrm{mL}$ and $20 \mathrm{ng} / \mathrm{mL}$ for the first month, between $10 \mathrm{ng} / \mathrm{mL}$ and $15 \mathrm{ng} / \mathrm{mL}$ from months one to nine, and between $5 \mathrm{ng} / \mathrm{mL}$ and $10 \mathrm{ng} / \mathrm{mL}$ after nine months from transplantation. Cyclosporine is only considered in the presence of tacrolimus intolerance. As an antiproliferative agent, we considered mycophenolate mofetil $1 \mathrm{~g}$ pre-transplant if there was no induction therapy and $1 \mathrm{~g}$ twice on the first day. Then it is tapered from $0.5 \mathrm{~g}$ to $2 \mathrm{~g}$ twice daily. Indications for discharge consisted of oral prednisone twice daily in descending doses of $5 \mathrm{mg}$ every three days until reaching $10 \mathrm{mg} /$ day, oral tacrolimus twice daily with serum controls at regular time intervals, mycophenolate mofetil twice daily, and, eventually, everolimus. Endomyocardial biopsies were performed before discharge, in the second month, the third month, the sixth month, and one year after transplantation.

\section{Statistical Analysis}

Frequencies and percentages of qualitative variables were calculated, and arithmetic means and standard deviations of quantitative variables. Averages were compared using the Student's test for independent samples, verifying the variables' normality using the Shapiro-Wilk test. In the absence of normal distribution, the Mann-Whitney $\mathrm{U}$ test was used. The value of $\mathrm{p}<0.05$ was accepted to determine the significant differences in the statistical tests. Kaplan-Meier survival analysis was performed with the log-rank test to compare the survival distributions of the samples. The analysis was performed using SPSS Statistics 24.

\section{Results}

Recipients' Age and Sex

The mean age at HTx was $41.2 \pm 17$ years ( 5 - 69 years), 73 (88\%) were adult, and 57 (68.7\%) were male. The number of HTx performed according to the recipients' sex and age group per year is shown in Figure 1. It was observed an average of $8.3 \mathrm{HTx}$ per year. A consecutive increase from $1 \mathrm{HTx}$ in $2010 \mathrm{HTx}$ to 13 in 2014. Then, it decreased to 5 by 2016, and a maximum of 14 in 2019. Recipients' characteristics at HTx are shown in Table 1.

\section{Surgical Indications, Clinical Profile, and Comorbidities}

The main indications for HTx included idiopathic dilated cardiomyopathy (DCM) in 55 (66.3\%) patients and ischaemic cardiomyopathy in $15(18.1 \%)$ patients. The other indications are also shown in Table 1.

The general preoperative left ventricular ejection fraction (LVEF) was $22.9 \pm 14.5 \%$ (6 - 70\%). In male, the LVEF was $19.9 \pm 10.6 \%(6-67 \%)$, compared with $29.3 \pm 19.3 \%(10-70 \%)$ in female. As for adults, the LVEF was $22.4 \pm 14.6 \%$ (6 - 70\%), compared with $26.2 \pm 13.6 \%$ (10 - 57\%) in pediatric patients. Overall, 74 $(89.2 \%)$ patients had a reduced LVEF $(<40 \%)$. There was a significant difference between sexes $(\mathrm{p}=0.04)$ but not between age groups $(\mathrm{p}=0.19)$ regarding the preoperative LVEF.

According to their clinical profile and condition, 61 recipients (73.5\%) were clinically categorized as Interagency Registry for Mechanically Assisted Circulatory Support (INTERMACS) Profile 3 before transplantation (11). Thus, $45(54.2 \%)$ were on intravenous inotropic support, of which $12(14.5 \%)$ required mechanical assist device support: 5 of them with intra-aortic balloon pump (IABP), 4 had an implanted left ventricular assist device (VAD), and 3 had an implanted bi-VAD (Thoratec Corporation, CA, USA).

Among comorbidities, the most frequent were pulmonary hypertension (25.3\%), hypothyroidism (19.3\%), chronic kidney disease (15.7\%), arterial hypertension (14.5\%), and diabetes mellitus (8.4\%).

Catheterization variables 
From the recipients' preoperative catheterization evaluation, the averages of a mean pulmonary artery pressure $(\mathrm{mPAP})$ of $35.2 \pm 10.1 \mathrm{mmHg}(13-55 \mathrm{mmHg})$, a pulmonary vascular resistance (PVR) of $3.2 \pm 2.1$ $\mathrm{uW}(0.3-11.1 \mathrm{uW})$, and a transpulmonary pressure gradient $(\mathrm{TPG})$ of $10.7 \pm 5.4 \mathrm{mmHg}(1-25 \mathrm{mmHg})$. The differences in the means between sexes and age groups were not significant in mPAP $(\mathrm{p}=0.26)(\mathrm{p}=$ $0.37)$, PVR $(\mathrm{p}=0.19)(\mathrm{p}=0.90)$, nor TPG $(\mathrm{p}=0.19)(\mathrm{p}=0.07)$, respectively.

\section{Surgical Procedure and Times}

The most performed surgical technique was the bicaval/unipulmonar $(96.4 \%)$; however, in $3(3.6 \%)$ cases, biatrial surgery was performed before institutional surgical consensus. Thirteen patients $(15.7 \%)$ had a previous sternotomy. An extension of the inferior vena cava with a bovine pericardial patch and another with a dacron tube had to be performed in 2 children. Two patients underwent combined simultaneous heart and kidney transplantation from the same donor. Three patients (3.6\%) left the operating room with extracorporeal membrane oxygenation (ECMO) support.

Mean recipients' waiting time was $12.7 \pm 28$ weeks ( 0 - 232 weeks $)$, mean ischemia time was $3.1 \pm 1.2$ hours (1.3 - 6.4 hours), mean operating time was $6.1 \pm 1.9$ hours (3.1 - 15.2 hours), mean cardiopulmonary bypass (CPB) time was $3 \pm 1.5$ hours $(1.3-11.1$ hours), and mean aortic cross-clamp time was $1.7 \pm 0.8$ hours $(0.8-6.8$ hours $)$. Regarding the waiting time, there were no significant differences between sexes $(\mathrm{p}=0.57)$ but there were between age groups $(\mathrm{p}=0.01)$ with an average time in adults of $8.9 \pm 13.2$ weeks, compared with $40.6 \pm 69.3$ weeks in children. On the other hand, there were no significant differences between sexes and age groups of ischemia $(\mathrm{p}=0.18)(\mathrm{p}=0.12)$, operating $(\mathrm{p}=0.41)(\mathrm{p}=0.94), \mathrm{CPB}(\mathrm{p}=0.41)(\mathrm{p}=$ $0.30)$, nor aortic cross-clamp $(\mathrm{p}=0.42)(\mathrm{p}=0.52)$ times, respectively.

\section{Postoperative Complications and Times}

The postoperative complications after HTx are shown in Table 2. The early complications were considered during the first 72 hours postoperative and the late after that period. During follow-up, three patients developed arterial hypertension, three diabetes mellitus, and 1 case of ascending aortic pseudoaneurysm in a child treated successfully with an endovascular stents placement (12). Neoplasms were not documented.

Mean postoperative intensive care unit (ICU) stay was $14.2 \pm 14.1$ days ( 1 - 84 days), mean postoperative hospital stay was $37.1 \pm 26.3$ days ( 1 - 165 days), and mean total hospital stay was $56.1 \pm 41.7$ days (3 - 178 days). In the evaluation of the postoperative ICU stay, the readmission cases were not considered. The postoperative hospital stay ranged from admission to the ICU until discharge, and the total hospital stays from admission to INCOR until discharge. There were no significant differences between sexes and age groups of postoperative ICU $(\mathrm{p}=0.15)(\mathrm{p}=0.53)$, postoperative hospital $(\mathrm{p}=0.61)(\mathrm{p}=0.98)$, nor total hospital $(\mathrm{p}=0.59)(\mathrm{p}=0.54)$ stays, respectively.

\section{Causes of Death}

One patient died during surgery due to cardiogenic shock. In this case, the surgical indication was EHF due to Fontan failure, and it had 6.8 and 11.5 hours of ischemia and surgical time, respectively. There were 82 surviving recipients. The postoperative mortality was $15.9 \%$ (13 patients), and the principal causes of death were infection in 6 patients and acute rejection in 5 . Hospital mortality was $7.3 \% ; 2$ died in the post-HTx 72-hours, one from cardiogenic shock, and one during reoperation due to revision of hemostasis. After the post-HTx 72-hours, three patients died from septic shock and one from acute humoral rejection. During the follow-up after hospital discharge, three patients died from cardiogenic shock due to $3 \mathrm{R}$ acute cellular rejection, two from septic shock, one from massive pulmonary thromboembolism, and one from septic and cardiogenic shock due to 3R acute cellular rejection. One of the recipients, who died from cardiogenic shock due to $3 \mathrm{R}$ acute cellular rejection, had blood type $\mathrm{O}$ - while the heart donor was $\mathrm{O}+$. Causes of death after HTx are shown in Table 3.

\section{Survival and the Influence of Recipients' Sex and Age Group}

The global survival at one, five, and ten years was $87.5 \%, 79.8 \%$, and $79.8 \%$, respectively (Figure 2). Se- 
parately, survival per recipient's sex at one, five, and ten years in male were $87.3 \%, 83,1 \%$, and $83.1 \%$, respectively, compared with 1-year's $87.9 \%$ and 5 -year's $73.3 \%$, in female $(\mathrm{p}=0.66)$ (Figure 3). Besides, pediatric patients' survival was $100 \%$ in all years, and in adults, $85 . \%$ in 1-year and $77.4 \%$ in five and ten years $(\mathrm{p}=0.17)($ Figure 4$)$.

\section{Discussion}

Through scientific development, ongoing training, and spreading program formation, HTx is now, to a greater extent, a better opportunity for the treatment of EHF patients around the world (5,13-16). However, only 102 countries report their numbers annually to the International Registry in Organ Donation and Transplantation (IRODaT) database (5). Given this development, some Latin American countries have reported their results, showing that HTx programs are feasible in developing countries (6-8). Approximately nine transplants were performed in Peru during the 1990s in different national centers in Lima $(1,7)$. Although this initiative was bringing unhurried but worthy results, it declined due to the lack of funding and political interest (1). For this reason, it was not until 2010 that the INCOR's Program was reactivated without interruption until this study was carried out.

In this first decade, a total of 83 HTx were studied. Despite the program's effort, according to the IRODaT database in 2019, Peru is one of the countries with the lowest rate of HTx, with 14 HTx per year (5). The USA, France, Brazil, Spain, and Argentina led with 3587, 434, 381, 300, and 123 HTx per year, respectively (5). From another perspective, the average HTx frequency in these ten years in Peru was 8.3 HTx per year. In this regard, from 2013 to date, we reported a number greater than or equal to 9 HTx per year. According to Bocchi et al. , this frequency is sufficient not to be associated with an increased risk of death (19). Nevertheless, in 2016 only 5 HTx were performed in total due to institutional management changes. Additionally, Peru had a 0.5 HTx per million population (pmp) rate while the USA, Croatia, Spain, Uruguay, and Argentina had 10.9, 9.3, 6.5, 3.9, and 2.8 HTx pmp, respectively (5). This data also placed us as one of the countries with the lowest HTx pmp regionally and globally in 2019.

In our study, $68.7 \%$ were male. Although $76.9 \%$ of women had reduced LVEF, there was a significant difference between preoperative LVEF between the sexes. This could be related to the lower number of female recipients and the higher percentage $(94.7 \%)$ of males with EHF with reduced LVEF. In addition, the low percentage of pediatric HTx is related to the lower rate of pediatric donors, and it is reflected in the significant difference regarding the waiting time, in which adults' average was 8.9 weeks, and children's, 40.9 weeks. This phenomenon is widely reported $(15,16,18)$. In our experience, most of them have been children due to the lack of donors and the slowly growing number of HTx in developing countries, coinciding with regional experiences $(17,20)$.

Like ISHLT reports, our main indications were idiopathic DCM in $66.3 \%$ of HTx and ischaemic cardiomyopathy in $18.1 \%$ (21). Although Chagas disease continues to be a Latin American public health problem, we have no indications for HTx due to Chagas cardiomyopathy $(7,22)$. We consider that this is related to the underreporting of cases, and this local factor should be reevaluated since we are still a Chagas endemic country (23). Regarding pretransplant clinical status, $85.5 \%$ had an INTERMACS Profile 1 to 3, similar to ISHLT reports (24). It is a progressive increase of urgent HTx from $36.2 \%$ to $46.8 \%$ in the last decade in Spain; in our program, the average was $54.2 \%$ due to longer waiting times (15). On the contrary, $54.2 \%$ of recipients required inotropic support pretransplant, lower than ISHLT's (24). Since the REMATCH trial, it is well-known that mechanical circulatory support potentially reduces mortality, increases survival, and improves the quality of life of transplanted recipients (25). Consequently, the ISHLT reports a gradual increase in VADs as bridge-to-transplant in $23 \%$ by 2005 and $50.3 \%$ by 2019 (24). Likewise, Gonzales et al. describe an inverse relationship in the use of IABPs and VADs (15). Our program utilized mechanical support in $14.5 \%$ of patients: $6 \%$ with IABP and $9.6 \%$ with VADs.

Even though having elevated catheterization values and pulmonary hypertension in $25.3 \%$ of cases, reversibility of these values was achieved through pretransplant pharmacological and mechanical support avoiding high incidences of graft failure (18). Furthermore, the world's average waiting time is 10 weeks; our recipients 
expected an adequate average of 12.7 weeks compared to $25,22.6$, and 4.1 weeks in the USA, Australia-New Zealand, and Chile, respectively $(8,26,27)$. The optimal ischemia time is a maximum of 4 to 6 hours, and we had a mean of 3.1 hours (28). We associate this result with the speed of the system when the National Donor Alert is activated.

Our mean postoperative stays in ICU and hospital were higher than reported in the USA, Brazil, and Chile $(8,14,28)$. Consistent with most reports, infection was the first cause of death after HTx; however, the second cause was acute rejection, unlike other series, which was primary graft failure $(2,13,15)$. Our overall survival rate was slightly higher than that described by the ISHLT at one, five, and ten years after HTx, and the analysis by age group was also higher, especially in children, as they still have a $100 \%$ survival (3). Consistently, we neither found significant differences in survival rates between the sexes. These results are subject to a limited number of HTx performed and a still short follow-up, especially in children, so future analyses are required. Although the ISHLT describes significant differences between the survival rates of adults recipients by sex, we did not found them, but a notable decrease in the females' from $87.9 \%$ at one year to $73.3 \%$ at five years, while in males, the difference was minor from $87.3 \%$ to $83.1 \%$ (3). Indeed, Bocchi et al. describe female recipients, in experimental models, may require increased immunosuppression due to higher frequency of rejection, and this may not be related to sex as such but to a previous pregnancy, a variable not considered in this study (19).

The study's limitations include the lack of data in the clinical histories on the profile of the donors and the short follow-up time concerning the appearance of complications. We agree and suggest that with wellselected donors, a careful evaluation of recipients, and a strict follow-up by a multidisciplinary team, suitable results can be reached in developing countries $(18,28)$.

\section{Conclusion}

In summary, HTx remains the treatment of choice for most EHF patients. Our patients' postoperative complications, mortality, and survival rates coincided with those reported by the ISHLT registry. However, no survival adjustment was made according to postoperative complications or multivariate analysis of the profiles. The careful receptor and donor selection, advancement in immunosuppression protocol, and the early detection of postoperative complications have allowed us to perform HTx in our institution with acceptable results compared to others worldwide.

\section{Acknowledgments}

The authors would like to thank all the people involved in the Peruvian National Heart Institute's Heart Transplantation Program. We would also like to highlight and appreciate the decision of donors and their families.

\section{Conflict of Interest: None}

\section{Data Availability Statement}

The data underlying this article will be shared on reasonable request to the corresponding author.

\section{ORCID iD}

Miguel Pinto-Salinas https://orcid.org/0000-0001-5789-3960

Julio Morón-Castro https://orcid.org/0000-0002-7964-7311

Fernando Chavarri-Velarde https://orcid.org/0000-0003-2524-0003

Franz Soplopuco-Palacios https://orcid.org/0000-0003-2100-3537

Luis Palma-Ortecho https://orcid.org/0000-0002-5874-127X

Miguel Lescano-Alva https://orcid.org/0000-0001-8177-9965

\section{References}


1. Pinto-Salinas M. Características Clínico-Quirúrgicas de los Trasplantes Cardiacos del Instituto Nacional Cardiovascular "Carlos Alberto Peschiera Carrillo" 1993 - 2019 [Tesis para optar el Título Profesional de Médico Cirujano]. [Facultad de Medicina, Escuela Profesional de Medicina Humana]: Universidad Nacional Mayor de San Marcos; 2020.

2. Lund LH, Khush KK, Cherikh WS, Goldfarb S, Kucheryavaya AY, Levvey BJ, et al. The Registry of the International Society for Heart and Lung Transplantation: Thirty-fourth Adult Heart Transplantation Report-2017; Focus Theme: Allograft ischemic time. J Heart Lung Transplant Off Publ Int Soc Heart Transplant. 2017;36(10):1037-46.

3. Khush KK, Cherikh WS, Chambers DC, Harhay MO, Hayes D, Hsich E, et al. The International Thoracic Organ Transplant Registry of the International Society for Heart and Lung Transplantation: Thirty-sixth adult heart transplantation report - 2019; focus theme: Donor and recipient size match. J Heart Lung Transplant. 2019 Oct;38(10):1056-66.

4. Barnard CN. A human cardiac transplant: An interim report of a successful operation performed at Groote Schuur Hospital, Cape Town. SAMJ South Afr Med J. 1967;41(48):1271-4.

5. International Registry on Organ Donation and Transplantation (IRODaT). Donations in 2019 (Database).

6. Sociedad de Trasplante de America Latina y el Caribe. Registros - Latin America Transplantation Registry Report 2015-2016.

7. Aguilar C, Alarco W, Soplopuco F, Morón J, Lescano M, Morales J, et al. Patología del trasplante cardiaco en el Perú: Experiencia con 61 casos en un centro de referencia nacional. Rev Peru Med Exp Salud Pública. 2018 Jun;35:241-9.

8. Villavicencio M, Rossel V, Larrea R, Peralta JP, Larraín E, Sung Lim J, et al. Experiencia clínica con 53 trasplantes cardiacos consecutivos. Rev Médica Chile. 2013 Dec;141(12):1499-505.

9. Rojas-Contreras C, De la Cruz-Ku G, Valcarcel-Valdivia B. Noninfectious and Infectious Complications and Their Related Characteristics in Heart Transplant Recipients at a National Institute. Exp Clin Transplant Off J Middle East Soc Organ Transplant. 2018 Apr;16(2):191-8.

10. Sarsam MA, Campbell CS, Yonan NA, Deiraniya AK, Rahman AN. An alternative surgical technique in orthotopic cardiac transplantation. J Card Surg. 1993 May;8(3):344-9.

11. Stevenson LW, Pagani FD, Young JB, Jessup M, Miller L, Kormos RL, et al. INTERMACS profiles of advanced heart failure: the current picture. J Heart Lung Transplant Off Publ Int Soc Heart Transplant. 2009 Jun;28(6):535-41.

12. Skrabonja-Crespo A, Chavarri-Velarde F, Pinto-Salinas M, Tauma-Arrue A. Percutaneous endovascular management of ascending aortic pseudoaneurysm after heart transplantation in a pediatric patient. Pediatr Transplant. 2020;25(3):e13958.

13. Udovicic M, Grizelj D, Mihajlović V, Falak H, Jordan A, Rudez I, et al. Heart transplantation results from the Department of Cardiology at Dubrava University Hospital. Cardiol Croat. 2021 Jan;16:33-33.

14. Awad M, Czer LSC, Mirocha J, Ruzza A, de Robertis M, Rafiei M, et al. Similar Mortality and Morbidity of Orthotopic Heart Transplantation for Patients 70 Years of Age and Older Compared With Younger Patients. Transplant Proc. 2016 Oct;48(8):2782-91.

15. González-Vilchez F, Almenar-Bonet L, Crespo-Leiro MG, Gómez-Bueno M, González-Costello J, PérezVilla F, et al. Spanish Heart Transplant Registry. 31th Official Report of the Heart Failure Association of the Spanish Society of Cardiology. Rev Esp Cardiol Engl Ed. 2020 Nov;73(11):919-26.

16. Khush KK, Potena L, Cherikh WS, Chambers DC, Harhay MO, Hayes D, et al. The International Thoracic Organ Transplant Registry of the International Society for Heart and Lung Transplantation: 37th 
adult heart transplantation report-2020; focus on deceased donor characteristics. J Heart Lung Transplant. 2020 Oct;39(10):1003-15.

17. Avila MS, Belfort D de SP. Progress in Heart Transplantation in Brazil: is it Time to Build a National Database? Arq Bras Cardiol. 2021 Apr;116:754-5.

18. Peradejordi M, Favaloro L, Vigliano C, Renedo M, Martínez L, Moscoloni S, et al. Resultados del trasplante cardíaco según el perfil clínico del receptor: 21 años de experiencia. Rev Argent Cardiol. 2016 Jun; 84 .

19. Bocchi EA, Fiorelli A, First Guideline Group for Heart Transplantation of the Brazilian Society of Cardiology. The Brazilian experience with heart transplantation: a multicenter report. J Heart Lung Transplant Off Publ Int Soc Heart Transplant. 2001 Jun;20(6):637-45.

20. Javier M, Delmo E, Hetzer R. Evolution of heart transplantation since Barnard's first. Cardiovasc Diagn Ther. 2021 Feb 1;11:171-82.

21. Lund LH, Edwards LB, Dipchand AI, Goldfarb S, Kucheryavaya AY, Levvey BJ, et al. The Registry of the International Society for Heart and Lung Transplantation: Thirty-third Adult Heart Transplantation Report-2016; Focus Theme: Primary Diagnostic Indications for Transplant. J Heart Lung Transplant Off Publ Int Soc Heart Transplant. 2016;35(10):1158-69.

22. Vieira J, Tavora F, Sobral M, Vasconcelos G, Almeida G, Fernandes J, et al. Chagas Cardiomyopathy in Latin America Review. Curr Cardiol Rep. 2019 Feb;21(2):8.

23. Vega S, Cabrera R, Alvarez C, Uribe-Vilca I, Guerrero-Quincho S, Ancca J, et al. Clinical and epidemiological characteristic of cases of Acute Chagas Disease in the Peruvian Amazon Basin, 2009-2016. Rev perú med exp salud publica. 2021 Feb;38(1):70-6.

24. Goldstein D, Meyns B, Xie R, Cowger J, Pettit S, Nakatani T, et al. Third Annual Report From the ISHLT Mechanically Assisted Circulatory Support Registry: A comparison of centrifugal and axial continuous-flow left ventricular assist devices. J Heart Lung Transplant. 2019 Apr 1;38:352-63.

25. Rose E, Moskowitz A, Packer M, Sollano J, Williams D, Tierney A, et al. The REMATCH trial: rationale, design, and end points. Randomized Evaluation of Mechanical Assistance for the Treatment of Congestive Heart Failure. Ann Thorac Surg. 1999 Mar;67(3):723-30.

26. Goldstein BA, Thomas L, Zaroff JG, Nguyen J, Menza R, Khush KK. Assessment of heart transplant waitlist time and pre- and post-transplant failure: A mixed methods approach. Epidemiol Camb Mass. 2016 Jul;27(4):469-76.

27. Ruygrok P, Pettersson R, Keogh A, Bergin P, Weintraub R, Dembo L, et al. Factors Influencing Waiting Time on the Heart Transplant Waiting List in Australia and New Zealand. J Heart Lung Transplant. 2014 Apr;33(4):S262.

28. Bruschi G, Colombo T, Oliva F, Botta L, Morici N, Cannata A, et al. Heart transplantation: 25 years' single-centre experience. J Cardiovasc Med Hagerstown Md. 2013 Sep;14(9):637-47.

Figures

Figure 1. Number of heart transplantations performed per year.A, According to the recipients' sex. B, According to the recipients' age group.

Figure 2. Kaplan-Meier survival curve after heart transplantations.

Figure 3. Kaplan-Meier survival curve after heart transplantations according to the recipients' sex.

Figure 4. Kaplan-Meier survival curve after heart transplantations according to the recipients' age group.

Tables 
Table 1. Recipients' characteristics at heart transplantation.

Table 2. Causes of death after heart transplantation.

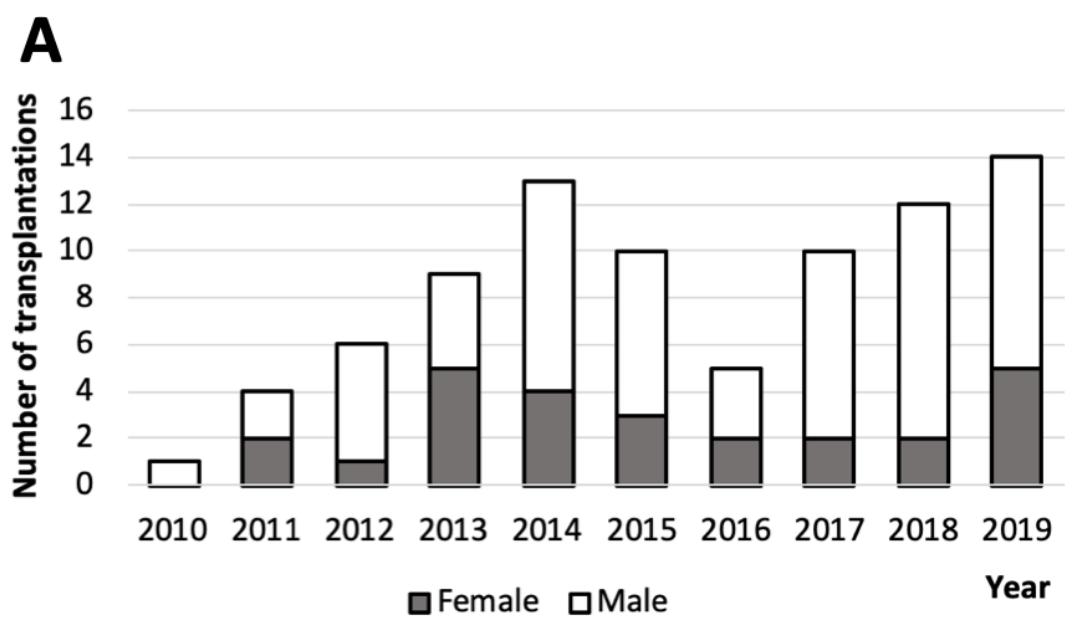

B

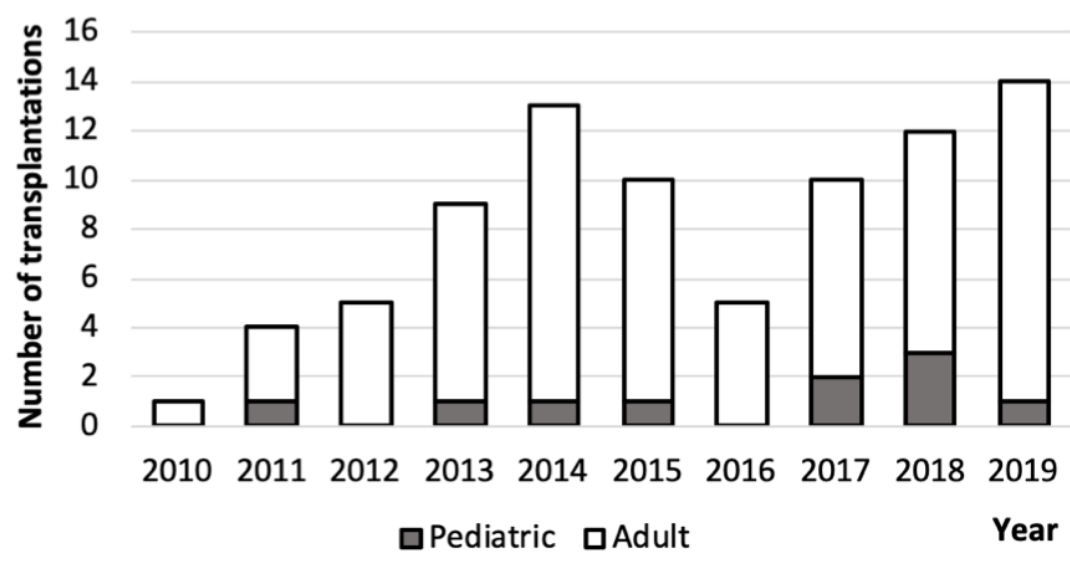



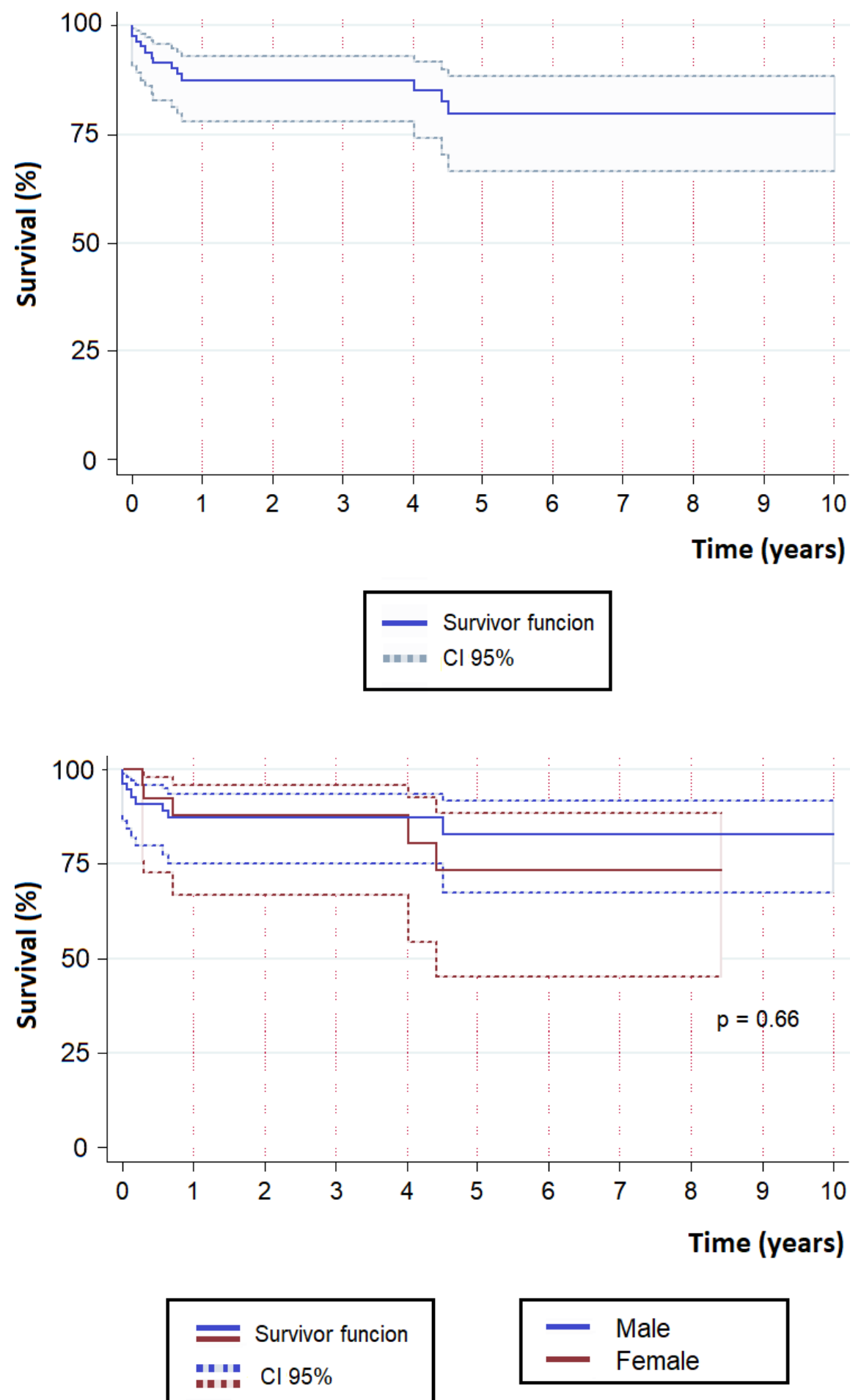

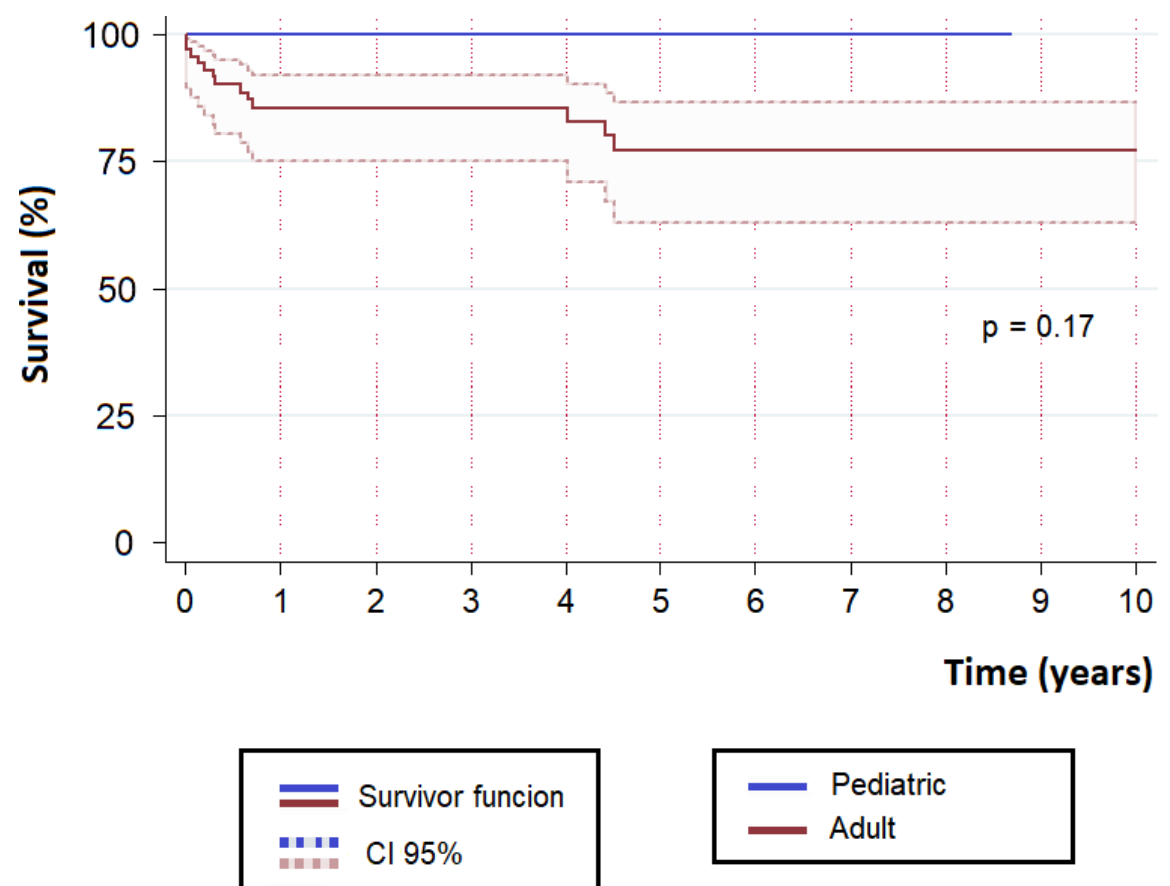

\section{Hosted file}

Table 1.docx available at https://authorea.com/users/356470/articles/543155-hearttransplantation-at-the-peruvian-national-heart-institute-one-decade-single-centerexperience

\section{Hosted file}

Table 2.docx available at https://authorea.com/users/356470/articles/543155-hearttransplantation-at-the-peruvian-national-heart-institute-one-decade-single-centerexperience

\section{Hosted file}

Table 3.docx available at https://authorea.com/users/356470/articles/543155-hearttransplantation-at-the-peruvian-national-heart-institute-one-decade-single-centerexperience 